\title{
Activities, Concentration Fluctuations and Complexing in Liquid Ca-Al Alloys
}

\author{
By K. T. Jacob*, S. Srikanth* and Y. Waseda**
}

\begin{abstract}
Activity of calcium in Ca-Al alloys $\left(X_{\mathrm{Ca}}<0.38\right)$ was determined by the Knudsen effusion technique. Activity of aluminium in Ca-rich alloys $\left(X_{\mathrm{Ca}}>0.44\right)$ was calculated from the measured distribution coefficient for aluminium between the alloy and a thin foil of pure iron, using data for the $\mathrm{Fe}-\mathrm{Al}$ system reported in the literature. By combining the results of Knudsen effusion and distribution studies with the Gibbs-Duhem relation, activities of both components and integral Gibbs energy of mixing for the complete composition range have been obtained at $1373 \mathrm{~K}$. The concentration-concentration structure factor of Bhatia and Thornton at zero wave vector has been computed from the thermodynamic data. The mean square thermal fluctuation in composition exhibits a minimum for the Ca-Al system at $X_{\mathrm{Ca}}=0.26$, suggesting the presence of a strong complex. The thermodynamic properties of the liquid alloy can be described by the associated solution model, with $\mathrm{Al}_{2} \mathrm{Ca}$ as the predominant complex. The thermodynamic properties computed on the mole fraction basis are more compatible with experimental data than those based on volume fraction.
\end{abstract}

(Received July 14, 1987)

Keywords: Knudsen effusion, distribution measurement, Gibbs energy of mixing, chemical potential, associated regular solution model, structure factor

\section{Introduction}

A knowledge of activities in liquid $\mathrm{Ca}-\mathrm{Al}$ alloys is of interest in understanding the physical chemistry of aluminothermic reduction of calcium oxide in vacuum. During this process a $\mathrm{Ca}-\mathrm{Al}$ alloy is formed which decreases the efficiency of utilisation of $\mathrm{Al}$ in the reduction process. The phase diagram for the $\mathrm{Ca}-\mathrm{Al}$ system shows an intermetallic phase $\mathrm{Al}_{2} \mathrm{Ca}$ congruently melting at $1352 \mathrm{~K}$ and $\mathrm{Al}_{4} \mathrm{Ca}$ melting incongruently at $973 \mathrm{~K}$. The intermetallic $\mathrm{Al}_{2} \mathrm{Ca}$ has potential application as a high temperature hydrogen storage medium. The free energy of formation of solid $\mathrm{Al}_{2} \mathrm{Ca}$ and $\mathrm{Al}_{4} \mathrm{Ca}$ has been measured by Notin and $\mathrm{Hertz}^{(1)}$ using a glavanic cell with $\mathrm{CaF}_{2}$ as the electrolyte at $800 \mathrm{~K}$. Veleckis ${ }^{(2)}$ has measured the free energy of formation of both compounds using a hydrogen titration method. The enthalpy of formation of compounds

* Department of Metallurgy, Indian Institute of Science, Bangalore 560 012, India.

** Institute of Mineral Dressing and Metallurgy (SENKEN), Tohoku University, Sendai 980, Japan.
$\mathrm{Al}_{2} \mathrm{Ca}, \mathrm{Al}_{4} \mathrm{Ca}$ and liquid alloys have been measured by Notin et $a l .^{(3)}$. More complete measurements for liquid compositions are given by Sommer et al. ${ }^{(4)}$ between 1125 and $1190 \mathrm{~K}$. Activities in liquid alloys at $1673 \mathrm{~K}$ have been measured by Schurmann et al. ${ }^{(5)}$ using a boiling point method. Since the aluminothermic reduction process is generally carried out at lower temperatures, activities have been measured in this study using a combination of Knudsen effusion and distribution measurements at $1373 \mathrm{~K}$.

\section{Experimental}

\section{Materials}

Calcium metal of $99.98 \%$ purity and aluminium of $99.99 \%$ purity were used in this study. The oxide crucibles for containing the alloy were prepared by isostatic pressing, followed by sintering at $1973 \mathrm{~K}$ for $\mathrm{CaO}, 1775 \mathrm{~K}$ for $\mathrm{Ca}_{3} \mathrm{Al}_{2} \mathrm{O}_{6}$ and $\mathrm{CaAl}_{2} \mathrm{O}_{4}$, for a total duration of $120 \mathrm{~h}$. The calcium aluminates were prepared by reacting $\mathrm{CaO}$ and $\mathrm{Al}_{2} \mathrm{O}_{3}$, obtained by thermal decomposition of high purity $\mathrm{CaCO}_{3}$ and $\mathrm{Al}_{2}\left(\mathrm{SO}_{4}\right)_{3}$ in vacuum at $800 \mathrm{~K}$, in 
Table 1 Composition of oxide crucible, orifice area, rate of weight loss of Knudsen cell and calculated vapour pressure of calcium over $\mathrm{Ca}-\mathrm{Al}$ alloys at $1373 \mathrm{~K}$.

\begin{tabular}{cllccc}
\hline \hline $\begin{array}{c}\text { Composition } \\
\text { of alloy } \\
X_{\mathrm{Ca}}\end{array}$ & $\begin{array}{c}\text { Crucible } \\
\text { material }\end{array}$ & $\begin{array}{c}\text { Orifice } \\
\text { area } \\
\left(\mathrm{cm}^{2}\right)\end{array}$ & $\begin{array}{c}\text { Clausing } \\
\text { factor } \\
f\end{array}$ & $\begin{array}{c}\text { Rate of } \\
\text { weight loss } \\
(\mathrm{g} / \mathrm{s})\end{array}$ & $\begin{array}{c}\text { Vapour pressure } \\
\text { of Ca } \\
(\mathrm{Pa})\end{array}$ \\
\hline 0.096 & $\mathrm{CaAl}_{2} \mathrm{O}_{4}$ & $7.86 \times 10^{-5}$ & 0.9977 & $1.72 \times 10^{-8}$ & 2.94 \\
0.096 & $\mathrm{CaAl}_{2} \mathrm{O}_{4}$ & $5.03 \times 10^{-5}$ & 0.9975 & $1.07 \times 10^{-8}$ & 2.86 \\
0.16 & $\mathrm{Ca}_{3} \mathrm{Al}_{2} \mathrm{O}_{6}$ & $5.03 \times 10^{-5}$ & 0.9975 & $3.17 \times 10^{-8}$ & 8.46 \\
0.21 & $\mathrm{Ca}_{3} \mathrm{Al}_{2} \mathrm{O}_{6}$ & $7.86 \times 10^{-5}$ & 0.9977 & $1.59 \times 10^{-7}$ & 27.15 \\
0.21 & $\mathrm{Ca}_{3} \mathrm{Al}_{2} \mathrm{O}_{6}$ & $3.14 \times 10^{-6}$ & 0.9959 & $5.82 \times 10^{-9}$ & 24.93 \\
0.30 & $\mathrm{CaO}$ & $5.03 \times 10^{-5}$ & 0.9975 & $7.21 \times 10^{-6}$ & 192.5 \\
0.30 & $\mathrm{CaO}$ & $3.14 \times 10^{-6}$ & 0.9959 & $4.50 \times 10^{-8}$ & 192.7 \\
0.33 & $\mathrm{CaO}$ & $7.86 \times 10^{-7}$ & 0.9957 & $1.65 \times 10^{-8}$ & 282.4 \\
0.38 & $\mathrm{CaO}$ & $7.86 \times 10^{-7}$ & 0.9957 & $3.00 \times 10^{-8}$ & 513.4 \\
\hline \hline
\end{tabular}

the appropriate ratio at $1625 \mathrm{~K}$. The formation of aluminates was confirmed by X-ray diffraction. Iron foil used for distribution studies was 99.99\% pure.

\section{Knudsen effusion studies}

Knudsen effusion studies on $\mathrm{Ca}-\mathrm{Al}$ alloys $\left(X_{\mathrm{Ca}} \leqslant 0.38\right)$ were conducted using cells made of titanium. The alloys were held in oxide crucibles. The stoichiometry of the oxide crucibles as a function of alloy composition is summarized in Table 1. Compatibility between the alloy and the crucible was established in preliminary experiments. The oxide phase that did not react with the alloy was selected as the crucible material. The oxide crucible approximately $1.5 \mathrm{~cm}$ in diameter was placed inside the Knudsen cell. For vapour pressure studies on pure calcium, the metal was contained directly in the titanium cell without an oxide crucible. The alloys, however, were not compatible with titanium containers. A schematic diagram of the Knudsen cell is shown in Fig. 1. A thin foil of titanium, $0.05 \mathrm{~mm}$ in thickness, was clamped between the lid and barrel sections of the Knudsen cell. Knudsen orifices ranging in diameter from 0.01 to $0.1 \mathrm{~mm}$ were made by laser drilling. The titanium foil near the orifice was thinned to give a knife edge. The diameters were measured under an optical microscope provided with a sensitive internal scale that could be superimposed on the orifice image. The orifice diameter at the experimental temperature was calculated from that at room temperature using the thermal expansion co- efficient for titanium.

The experimental arrangement was similar to that used earlier ${ }^{(6)-(8)}$. The Knudsen cell was suspended from a Cahn microbalance inside a vacuum furnace provided with tungsten resistance heater and molybdenum shields. The temperature of the furnace was controlled to $\pm 1 \mathrm{~K}$ and measured by a Pt/Pt-13\% Rh thermocouple, calibrated against the melting point of gold. The vacuum was generated by a diffusion pump backed by a mechanical rotary pump. A typical pressure inside the furnace during most of the measurements was $10^{-3} \mathrm{~Pa}$. Effusion measurements were carried out on pure $\mathrm{Ca}$ from 898 to $1245 \mathrm{~K}$ and six $\mathrm{Ca}-\mathrm{Al}$ alloys at $1373 \mathrm{~K}$. The composition of the alloy was determined by chemical analysis after each

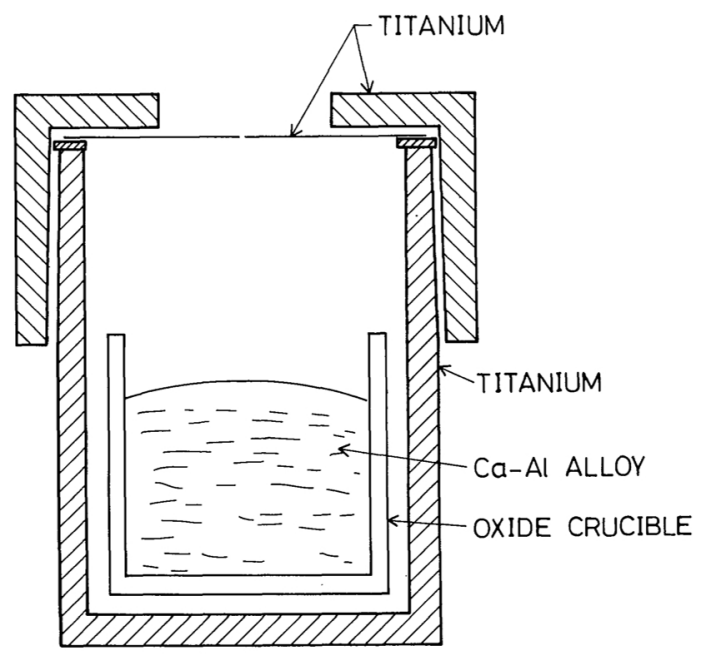

Fig. 1 Schematic diagram of the Knudsen cell. 
experiment.

\section{Distribution studies}

Liquid Ca-Al alloys, $X_{\mathrm{Ca}}>0.44$, contained in small crucibles made from pure iron foil approximately $0.05 \mathrm{~mm}$ in thickness were held at $1373 \mathrm{~K}$ for $90 \mathrm{~h}$. Aluminium diffused into the iron foil until equilibrium was attained between the foil and the liquid alloy. The alloys were found to creep out of the small iron crucibles during the course of the experiment. The thin walled crucibles were therefore kept in a larger iron crucible provided with a lid. The geometry of the larger iron crucible was similar to that of the Knudsen cell. The loss of calcium by preferential vapourization and consequent change in alloy composition was also minimized by enclosing the alloy in a closed cell. Preliminary experiments indicated that approximately $80 \mathrm{~h}$ were required for the attainment of equilibrium. After $90 \mathrm{~h}$ the crucible was quenched. The larger crucible was opened and the small crucible containing the alloy was sectioned and mounted for metallographic examination. The aluminium concentrations in the iron foil and $\mathrm{Ca}-\mathrm{Al}$ alloy were determined by EPMA. Concentrations of iron in the $\mathrm{Ca}$ $\mathrm{Al}$ alloy and of calcium in $\mathrm{Fe}-\mathrm{Al}$ foil were less than 0.5 at $\%$.

\section{Results}

\section{Knudsen effusion}

The vapour pressure of calcium was calculated from the rate of weight loss of Knudsen cell using the equation,

$$
P=2286 \frac{m}{f \cdot t \cdot A} \sqrt{\frac{T}{M}}
$$

where $P$ is the pressure in $\mathrm{Pa}, m$ is the weight loss in $g, t$ is time in s, $A$ is the area of Knudsen orifice in $\mathrm{cm}^{2}, T$ is temperature in Kelvin, $M$ is the molecular weight of the effusing species in $g$ and $f$ is the Clausing factor for nonideal orifice. The experimental data for $\mathrm{Ca}-\mathrm{Al}$ alloys at $1373 \mathrm{~K}$ are summarized in Table 1 . Clausing factors used in this study were taken from Iczkowski et al. ${ }^{(9)}$. The measured vapour pressure was found to be independent of orifice diameter for both pure $\mathrm{Ca}$ and $\mathrm{Ca}-\mathrm{Al}$ alloys within experimental error. This suggests the absence of surface depletion of alloys due to preferential vapourization of $\mathrm{Ca}$. The variation of the logarithm of the saturation vapour pressure of pure calcium is shown as a function of the reciprocal of absolute temperature in Fig. 2. The data obtained in this study agree almost exactly with the data recommended by Hultgren et al. ${ }^{(10)}$ from 898 to $1176 \mathrm{~K}$. At higher temperatures the vapour pressures obtained in this study are progressively higher. This is almost certainly due to deviations from purely molecular flow resulting from the shorter mean free path of the molecules. The vapour pressure of pure calcium at $1176 \mathrm{~K}$ is $501 \mathrm{~Pa}$. This is probably the highest partial pressure of calcium that can be measured by the Knudsen technique with the experimental arrangement used in this study. This corresponds to a ratio of $\lambda / d \simeq 1$, where $\lambda$ is the mean free path of calcium atoms and $d$ is the orifice diameter. Studies by Carlson et al. ${ }^{(11)}$ also indicate that the upper limit for the

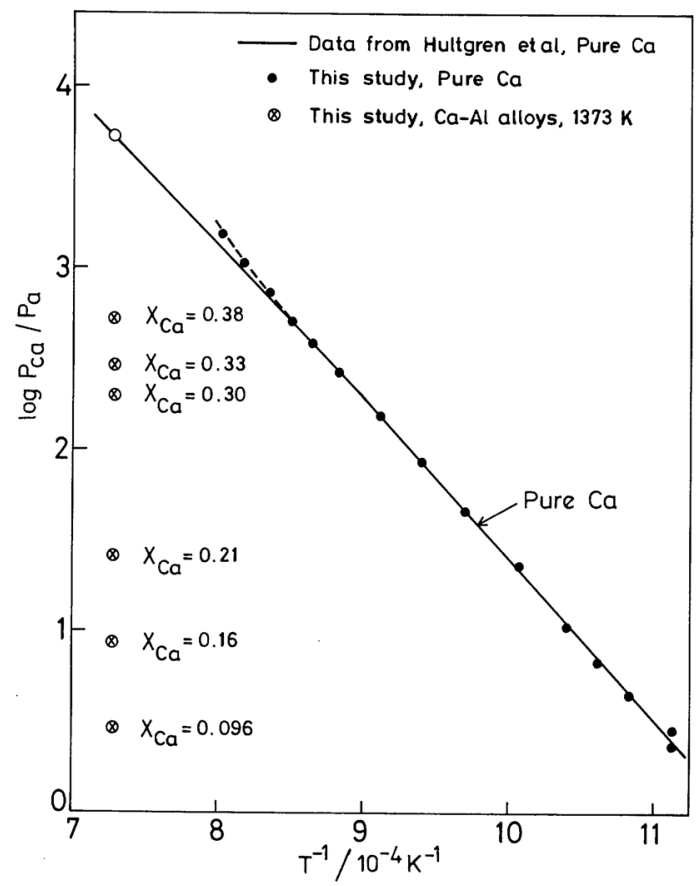

Fig. 2 Variation of the logarithm of saturation vapour pressure of calcium over the pure metal with reciprocal of absolute temperature. The vapour pressure of calcium over $\mathrm{Ca}-\mathrm{Al}$ alloys at $1373 \mathrm{~K}$ are also indicated. 
Knudsen effusion technique corresponds to $\lambda / d \simeq 1$.

The partial pressure of $\mathrm{Ca}$ over the alloys at $1373 \mathrm{~K}$ is shown in Fig. 2 along with their composition. Alloys containing $X_{\mathrm{Ca}}>0.38$ were not used since the partial pressure of Ca over these alloys would lie in a range where the Knudsen results would be unreliable. To compute activities of $\mathrm{Ca}$ in the alloy the vapour pressure of pure $\mathrm{Ca}$ at $1373 \mathrm{~K}$ is taken from Hultgren et $a{ }^{(10)}$. The composition dependence of the activity of calcium at $1373 \mathrm{~K}$ is shown in Fig. 3 for $X_{\mathrm{Ca}} \leqslant 0.38$.

\section{Distribution measurements}

The activities of each component in phases at equilibrium are equal. Since the two phases in equilibrium are essentially binary containing less than 0.5 at $\%$ of the third element, the activity-composition relationship for liquid $\mathrm{Ca}-\mathrm{Al}$ alloys can be derived from the distribution ratio for aluminium and known activities in the binary $\mathrm{Fe}-\mathrm{Al}$ solid alloys ${ }^{(12)}$. The experimental data on the compositions of coexisting equilibrium phases are summarized in Table 2 along with the derived activity of aluminium

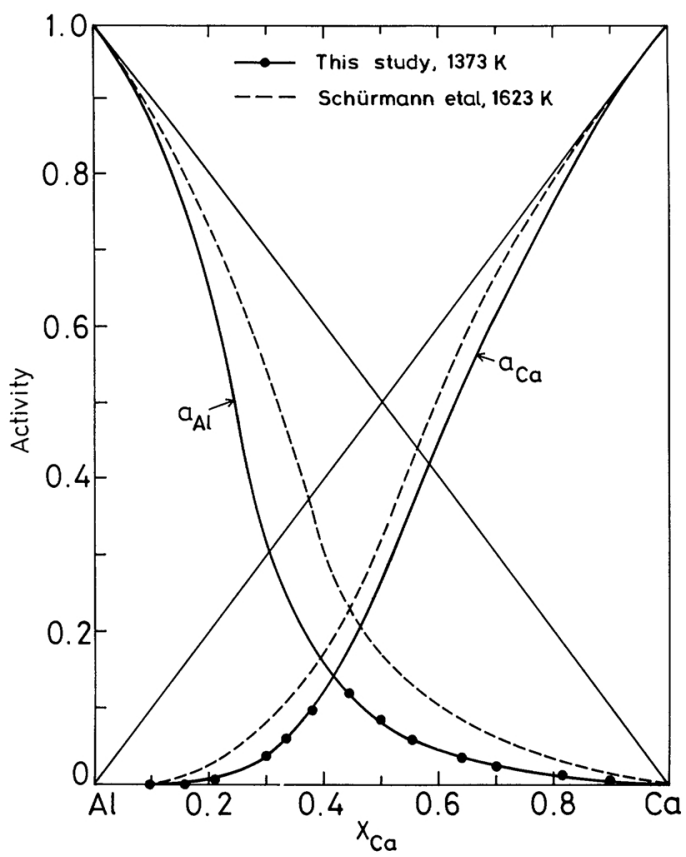

Fig. 3 Composition dependence of activities in $\mathrm{Ca}-\mathrm{Al}$ alloys at $1373 \mathrm{~K}$.
Table 2 Aluminium concentration of iron foils equilibrated with liquid $\mathrm{Ca}-\mathrm{Al}$ alloys at $1373 \mathrm{~K}$ and derived activites.

\begin{tabular}{cccc}
\hline \hline $\begin{array}{c}\text { Composition of } \mathrm{Ca}-\mathrm{Al} \\
\text { alloys }\end{array}$ & $\begin{array}{c}\text { Aluminium concen- } \\
\text { tration in solid iron, } \\
\text { at \% }\end{array}$ & $a_{\mathrm{Al}}^{*}$ \\
\hline at \% Al & at \% Ca & 13.1 & 0.005 \\
\hline 9.8 & 90.2 & 25.2 & 0.012 \\
18.6 & 81.4 & 36.3 & 0.026 \\
30.1 & 69.9 & 40.8 & 0.037 \\
36.2 & 63.8 & 45.1 & 0.060 \\
44.7 & 55.3 & 48.0 & 0.086 \\
50.2 & 49.8 & 50.2 & 0.120 \\
55.7 & 44.3 & \multicolumn{4}{l}{} \\
$*$ Relative to liquid aluminium, using the data of \\
Eldridge and Komarek ${ }^{(12)}$ for Fe-Al system
\end{tabular}

based on the data of Eldridge and Komarek ${ }^{(12)}$. The composition dependence of the measured activity of aluminium at $1373 \mathrm{~K}$ is shown in Fig. 3.

\section{Gibbs energy of mixing and concentration-concentration structure factor}

The activity coefficient of aluminium for the composition range $0.38 \geqslant X_{\mathrm{Ca}}>0$ at $1373 \mathrm{~K}$ were derived using the Gibbs-Duhem relation,

$$
\ln \gamma_{\mathrm{Al}}=\int_{X_{\mathrm{Ca}}=0}^{X_{\mathrm{Ca}}}-\frac{X_{\mathrm{Ca}}}{X_{\mathrm{Al}}} \mathrm{d} \ln \gamma_{\mathrm{Ca}}
$$

where $\gamma_{i}=a_{i} / X_{i}$. The composition dependence of $\ln \gamma_{\mathrm{Ca}}$ was evaluated from Knudsen effusion studies. Similarly the activity coefficient of calcium for $1>X_{\mathrm{Ca}}>0.44$ was derived by integration of the activity coefficient of aluminium obtained from distribution measurements. The activities of calcium and aluminium obtained by Gibbs-Duhem integration are plotted in Fig. 3 and joined smoothly with measured data. The actvities and activity coefficients for both components at $1373 \mathrm{~K}$ are given in Table 3 at regular intervals of composition. Gibbs energy of mixing computed from these activities is shown in Fig. 4 with respect to liquid $\mathrm{Ca}$ and $\mathrm{Al}$ as standard states. The concentration-concentration structure factor of Bhatia and Thornton at zero wave vector can be evaluated from the activity data: 
Table 3 Activities of $\mathrm{Ca}$ and $\mathrm{Al}$ in liquid $\mathrm{Ca}-\mathrm{Al}$ alloys at $1373 \mathrm{~K}$ derived from Knudsen effusion studies, distribution measurements and Gibbs-Duhem relation.

\begin{tabular}{lllll}
\hline \hline$X_{\mathrm{Ca}}$ & \multicolumn{1}{c}{$a_{\mathrm{Ca}}^{\dagger}$} & \multicolumn{1}{c}{$\gamma_{\mathrm{Ca}}^{\dagger}$} & \multicolumn{1}{c}{$a_{\mathrm{Al}}^{\dagger}$} & \multicolumn{1}{c}{$\gamma_{\mathrm{Al}}^{\dagger}$} \\
\hline 0 & 0 & & 1.0 & 1.0 \\
0.1 & $5.90 \times 10^{-4}$ & $5.90 \times 10^{-3}$ & 0.873 & 0.970 \\
0.2 & $3.60 \times 10^{-3}$ & $1.80 \times 10^{-2}$ & 0.645 & 0.806 \\
0.3 & $3.73 \times 10^{-2}$ & 0.124 & 0.300 & 0.429 \\
0.4 & 0.121 & 0.303 & 0.160 & 0.267 \\
0.5 & 0.264 & 0.528 & $8.49 \times 10^{-2}$ & 0.170 \\
0.6 & 0.446 & 0.743 & $4.52 \times 10^{-2}$ & 0.113 \\
0.7 & 0.611 & 0.873 & $2.50 \times 10^{-2}$ & $8.33 \times 10^{-2}$ \\
0.8 & 0.760 & 0.950 & $1.32 \times 10^{-2}$ & $6.60 \times 10^{-2}$ \\
0.9 & 0.894 & 0.993 & $5.01 \times 10^{-3}$ & $5.01 \times 10^{-2}$ \\
1.0 & 1.0 & 1.0 & 0.0 & \\
\hline \hline
\end{tabular}

$\dagger$ Relative to pure liquid $\mathrm{Ca}$ and $\mathrm{Al}$ as standard states

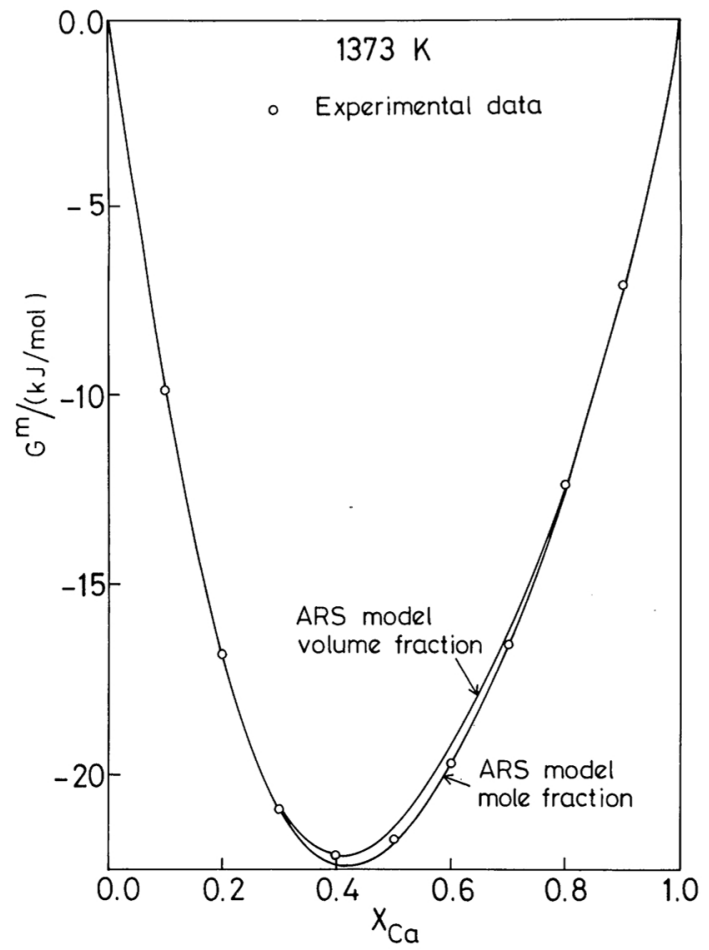

Fig. 4 Free energy of mixing of liquid $\mathrm{Ca}-\mathrm{Al}$ alloys at $1373 \mathrm{~K}$, with respect to pure liquid $\mathrm{Ca}$ and $\mathrm{Al}$ as standard states.

$$
S_{\mathrm{cc}}(0)=\left(1-X_{\mathrm{Ca}}\right)\left[\frac{\partial \ln a_{\mathrm{Ca}}}{\partial X_{\mathrm{Ca}}}\right]_{T, P}^{-1}
$$

The derived values are shown in Fig. 5. The structure factor is related to the mean square thermal fluctuation in composition:

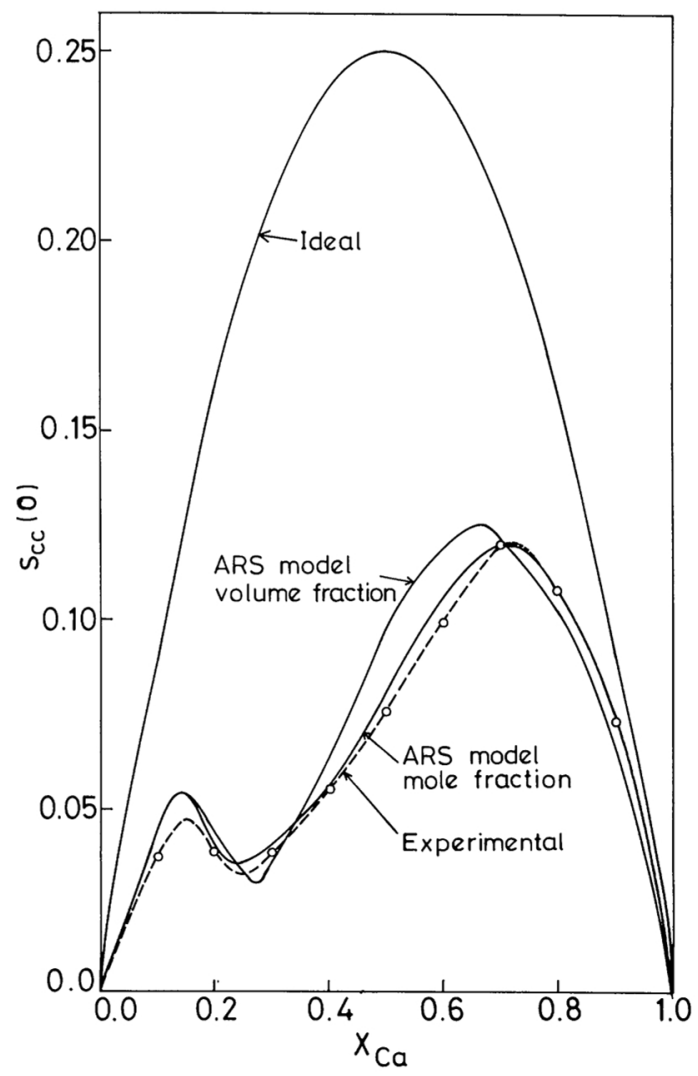

Fig. 5 Concentration-concentration structure factor at zero wave vector $\left(S_{\mathrm{cc}}(0)\right)$ for $\mathrm{Ca}-\mathrm{Al}$ alloys at $1373 \mathrm{~K}$.

$$
S_{\mathrm{cc}}(0)=\bar{N}\left\langle(\Delta c)^{2}\right\rangle
$$

where $\bar{N}$ is the average number of particles in a fixed volume $V$ and $\langle\Delta c\rangle$ is the mean square thermal fluctuation in concentration.

\section{Enthalpy and entropy of mixing}

The enthalpy of mixing for liquid $\mathrm{Ca}-\mathrm{Al}$ alloys have been measured by Sommer et al. ${ }^{(4)}$ between 1125 and $1190 \mathrm{~K}$ and Notin et al. ${ }^{(3)}$ between 950 and $1040 \mathrm{~K}$. Strictly, in systems which form complexes in the liquid state, the concentration of the complex and therefore the enthalpy of mixing are temperature dependent. The variation between 1125 and $1190 \mathrm{~K}$ in the study of Sommer et al. ${ }^{(4)}$ was found to be well within experimental error. The results are plotted in Fig. 6. If it is assumed that the enthalpy of mixing remains constant up to $1373 \mathrm{~K}$, then the results of this study may be combined with calorimetric information to deduce the entropy 


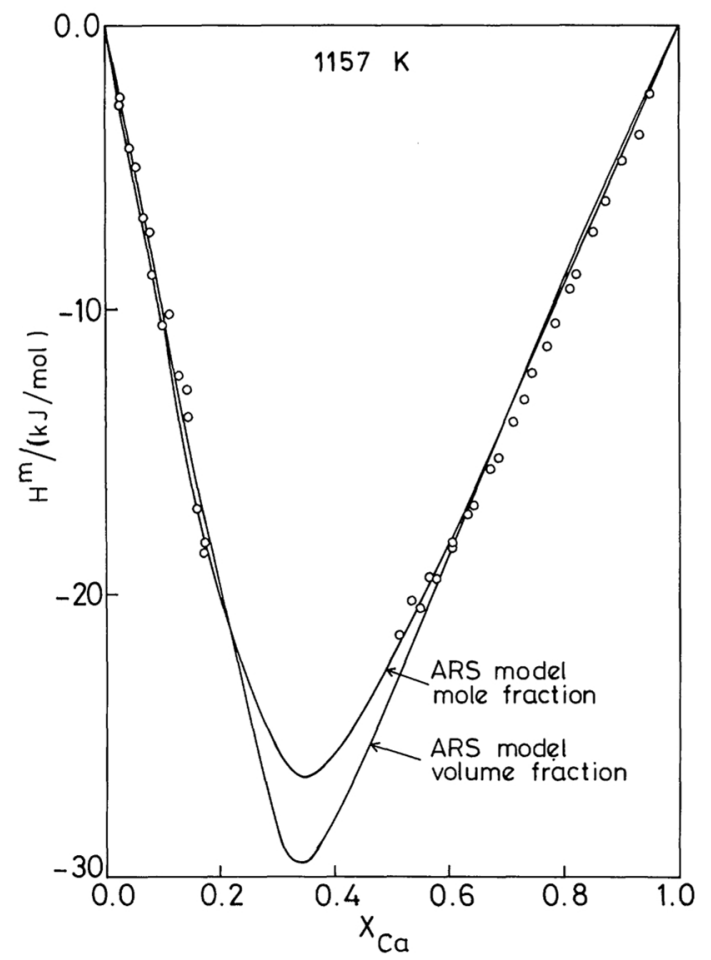

Fig. 6 Experimental $^{(4)}$ and calculated enthalpies of mixing of liquid $\mathrm{Ca}-\mathrm{Al}$ alloys at $1157 \mathrm{~K}$.

of mixing. The results are shown by points in Fig. 7. The entropy of mixing is negative from $X_{\mathrm{Ca}} \simeq 0.1$ to $X_{\mathrm{Ca}} \simeq 0.5$.

\section{Application of Regular Associated Solution Model}

Two different cases of regular associated solution can be considered. In the first ap$\operatorname{proach}^{(13)}$, the difference in sizes of the various constituents in the liquid solution are neglected and the free energy of mixing is given in terms of mole fraction. In the second ${ }^{(14)}$ volume effects are considered by approximating the volume of the individual atomic species to be the same and the volume of the complex to be a linearly additive function of the volume of the individual atoms of complex $\mathrm{A}_{\mu} \mathrm{B}$. Then the volume of the associate is $(\mu+1)$ times that of $\mathrm{A}$ or $\mathrm{B}$ atoms. In this case following Flory ${ }^{(15)(16)}$, the free energy of mixing is expressed in terms of volume fraction. In both cases it is further assumed that the interactions between the species is relatively small and hence

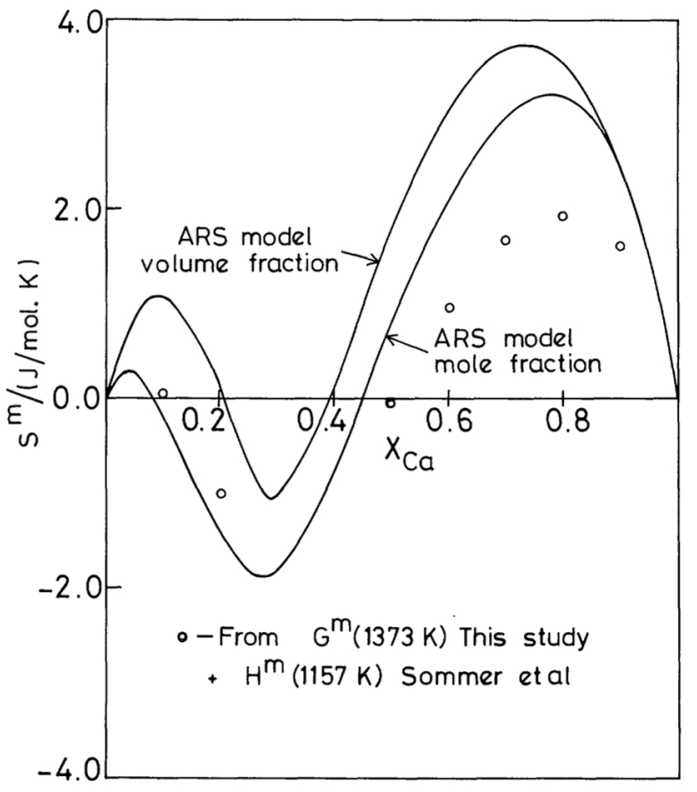

Fig. 7 Evaluated entropy of mixing using experimental data and regular associated solution models for the $\mathrm{Ca}-$ $\mathrm{Al}$ system at $1373 \mathrm{~K}$.

the higher order interactions can be neglected.

The enthalpy, entropy, free energy of mixing and $S_{\mathrm{cc}}(0)$ have been determined using these two approaches and compared with the experimental results.

\section{Model based on mole fraction composition variable}

In the absence of any contribution due to difference in sizes of the various constituents in the liquid solution, the free energy of mixing for a regular associated solution is given by

$$
\begin{aligned}
G^{\prime \mathrm{m}}= & -n_{3} g+R T \sum_{i=1}^{3} n_{i} \ln \left(\frac{n_{i}}{n}\right) \\
& +\sum_{i<j} \frac{n_{i} n_{j}}{n} \omega_{i j},
\end{aligned}
$$

where $n_{1}, n_{2}$ and $n_{3}$ are the number of moles of $\mathrm{A}$ atoms, $\mathrm{B}$ atoms and $\mathrm{A}_{\mu} \mathrm{B}$ complex respectively and $\omega_{i j}$ 's are the interaction energies. The values of $n_{1}, n_{2}$ and $n_{3}$ are related to the gross mole fractions $X_{1}$ and $X_{2}$ from the conservation of atoms.

$$
n_{1}=N X_{1}-\mu n_{3} ; n_{2}=N X_{2}-n_{3}
$$

and 


$$
n=n_{1}+n_{2}+n_{3} \text {. }
$$

The mole fractions of the species can be expressed as

$$
X_{i}=n_{i} / n=\frac{n_{i}}{N-\mu n_{3}} \quad \text { or } \quad n_{i}=X_{i} n=\frac{N X_{i}}{1+\mu X_{\mathrm{A}_{\mu} \mathrm{B}}},
$$

where $N$ is the total number of moles of $\mathrm{A}$ and $\mathrm{B}$ atoms in the liquid irrespective of their state of aggregation. The term $\left(-n_{3} g\right)$ in eq. (5) represents the lowering of free energy due to formation of the associate where $g$ is the free energy of dissociation of the complex, given by

$$
g=-R T \ln K,
$$

$K$ being the equilibrium constant for the reaction $\mathrm{A}_{\mu} \mathrm{B} \rightarrow \mu \mathrm{A}+\mathrm{B}$. Several approaches have been suggested by different investigators $^{(13)(14)(17)-(19)}$ to determine the concentration of the cluster, the interaction energies and the free energy of formation of the complex. Due to the transcendental nature of equations involved several investigators have resorted to simplifying assumptions such as equally strong interactions of the unassociated species with the complex ${ }^{(18)}$, ideal interaction ${ }^{(19)}$, preferred interaction $^{(18)}$ and approximation of the logarithm of the activity coefficients by a Taylor series expansion ${ }^{(17)}$. The procedure outlined by Bhatia and Hargrove ${ }^{(14)}$ though free of any simplifying assumptions, involves a tedious numerical procedure to determine the unknown parameters, $\omega_{i j}$ 's and $g$. More recently, Lele and $\mathrm{RaO}^{(13)}$ have developed procedures for estimating all the necessary parameters using the thermodynamic behaviour of the solutions at infinite dilution without any assumptions. This methodology is used in this study.

Lele and $\mathrm{RaO}^{(13)}$ have essentially considered an $\mathrm{A}_{\mu} \mathrm{B}$ type of complex and the concentration of the complex at any given gross concentration $X_{2}$ of the liquid alloy is determined from a knowledge of the thermodynamic behaviour of the solution at infinite dilution and the gross activities $a_{1}$ and $a_{2}$ of the two components through the relation (for $\mu>1$ );

$$
\begin{aligned}
\ln K+\frac{\omega_{13}}{R T}= & \left(\frac{1+X_{\mathrm{A}}}{X_{\mathrm{A}_{\mu} \mathrm{B}}}\right) \ln \left(\frac{a_{1}}{X_{\mathrm{A}}}\right)+\frac{X_{\mathrm{B}}}{X_{\mathrm{A}_{\mu} \mathrm{B}}} \\
& \times\left[\ln \left(\frac{a_{2}}{X_{\mathrm{B}}}\right)-\frac{\omega_{12}}{R T}\right]+\ln \frac{a_{1}^{\mu} a_{2}}{X_{\mathrm{A}_{\mu} \mathrm{B}}}
\end{aligned}
$$

by an iterative procedure. The left hand side of eq. (8) is given by,

$$
\ln K+\frac{\omega_{13}}{R T}=\ln \left(\frac{\gamma_{1}^{0} \gamma_{2}^{0}}{\gamma_{1}^{0}-\gamma_{2}^{0}}\right) .
$$

The interaction energy $\omega_{12}$ is related to the activity coefficient of component 1 at infinite dilution.

$$
\omega_{12}=R T \ln \gamma_{1}^{0} .
$$

The mole fractions $X_{\mathrm{A}}$ and $X_{\mathrm{B}}$ can be expressed in terms of $X_{\mathrm{A}_{\mu} \mathrm{B}}$, and the gross mole fraction $X_{2}$ by,

$$
X_{\mathrm{A}}=\left(1-X_{2}\right)\left(1+\mu X_{\mathrm{A}_{\mu} \mathrm{B}}\right)-\mu X_{\mathrm{A}_{\mu} \mathrm{B}}
$$

and

$$
X_{\mathrm{B}}=X_{2}\left(1+\mu X_{\mathrm{A}_{\mu} \mathrm{B}}\right)-X_{\mathrm{A}_{\mu} \mathrm{B}} .
$$

Lele and $\mathrm{RaO}^{(13)}$ have shown that specific values of $K, \omega_{13}$ and $\omega_{23}$ can then be determined from the value of $X_{\mathrm{A}_{\mu} \mathrm{B}}$ obtained by solving eq. (8) using the following equations:

$$
\begin{aligned}
\ln K= & \ln \frac{X_{\mathrm{A}}^{\mu} X_{\mathrm{B}}}{X_{\mathrm{A}_{\mu} \mathrm{B}}}+\frac{\omega_{12}}{R T}\left[\mu X_{\mathrm{B}}\left(1-X_{\mathrm{A}}\right)+X_{\mathrm{A}}\right]+\frac{\omega_{13}}{R T}\left[\mu X_{\mathrm{A}_{\mu} \mathrm{B}}\left(1-X_{\mathrm{A}}\right)-X_{\mathrm{A}}\right] \\
& +\frac{\omega_{23}}{R T}\left[X_{\mathrm{A}_{\mu} \mathrm{B}}\left(1-\mu X_{\mathrm{B}}\right)-X_{\mathrm{B}}\right], \\
\frac{\omega_{13}}{R T}= & \frac{X_{\mathrm{B}} \ln \left(\frac{a_{2}}{X_{\mathrm{B}}}\right)+\left(1-X_{\mathrm{B}}\right) \ln \left(\frac{a_{1}}{X_{\mathrm{A}}}\right)-X_{\mathrm{B}}\left(1-X_{\mathrm{B}}\right) \frac{\omega_{12}}{R T}}{X_{\mathrm{A}_{\mu} \mathrm{B}}^{2}}
\end{aligned}
$$

and 


$$
\frac{\omega_{23}}{R T}=\frac{X_{\mathrm{A}} \ln \left(\frac{a_{1}}{X_{\mathrm{A}}}\right)+\left(1-X_{\mathrm{A}}\right) \ln \left(\frac{a_{2}}{X_{\mathrm{B}}}\right)-X_{\mathrm{A}}\left(1-X_{\mathrm{A}}\right) \frac{\omega_{12}}{R T}}{X_{\mathrm{A}_{\mu} \mathrm{B}}^{2}} .
$$

The free energy of mixing per mole of A-B solution can be expressed in terms of the mole fractions of species by combining eqs. (5) and (7).

$$
\begin{aligned}
G^{\mathrm{m}}= & \frac{1}{\left(1+\mu X_{\mathrm{A}_{\mu} \mathrm{B}}\right)}\left(X_{\mathrm{A}} X_{\mathrm{B}} \omega_{12}+X_{\mathrm{A}} X_{\mathrm{A}_{\mu} \mathrm{B}} \omega_{13}+X_{\mathrm{B}} X_{\mathrm{A}_{\mu} \mathrm{B}} \omega_{23}\right) \\
& +\frac{R T}{\left(1+\mu X_{\mathrm{A}_{\mu} \mathrm{B}}\right)}\left(X_{\mathrm{A}} \ln X_{\mathrm{A}}+X_{\mathrm{B}} \ln X_{\mathrm{B}}+X_{\mathrm{A}_{\mu} \mathrm{B}} \ln X_{\mathrm{A}_{\mu} \mathrm{B}}\right)+\frac{X_{\mathrm{A}_{\mu} \mathrm{B}}}{\left(1+\mu X_{\mathrm{A}_{\mu} \mathrm{B}}\right)} \cdot R T \ln K .
\end{aligned}
$$

The values of the interaction energies and equilibrium constant obtained by this technique for the $\mathrm{Ca}-\mathrm{Al}$ system at $1373 \mathrm{~K}$ are listed in Table 4 . The free energy of mixing as a function of concentration obtained by this model for the $\mathrm{Ca}-\mathrm{Al}$ system at $1373 \mathrm{~K}$ is shown in Fig. 4 . The concentration fluctuations $S_{\mathrm{cc}}(0)$ at the zero-wave number limit is given by

$$
S_{\mathrm{cc}}(0)=R T\left(\frac{\partial^{2} G^{\mathrm{m}}}{\partial X_{1}^{2}}\right)_{T, P}^{-1}
$$

Using eq. (12) in (13), following Bhatia and Hargrove ${ }^{(14)}, S_{\mathrm{cc}}(0)$ can be written as

$$
S_{\mathrm{cc}}(0)=\frac{S_{\mathrm{cc}}}{1+D S_{\mathrm{cc}}} \text {. }
$$

Here

$$
\begin{aligned}
& S_{\mathrm{cc}}=\left(1+\mu X_{\mathrm{A}_{\mu} \mathrm{B}}\right)\left[\frac{\left(X_{\mathrm{A}}^{\prime}\right)^{2}}{X_{\mathrm{A}}}+\frac{\left(X_{\mathrm{B}}^{\prime}\right)^{2}}{X_{\mathrm{B}}}+\frac{\left(X_{\mathrm{A}_{\mu} \mathrm{B}}^{\prime}\right)^{2}}{X_{\mathrm{A}_{\mu} \mathrm{B}}}\right]^{-1} \\
& D=\frac{2}{R T\left(1+\mu X_{\mathrm{A}_{\mu} \mathrm{B}} \mathrm{B}\right.}\left[\omega_{12} X_{\mathrm{A}}^{\prime} X_{\mathrm{B}}^{\prime}+\omega_{23} X_{\mathrm{B}}^{\prime} X_{\mathrm{A}_{\mu} \mathrm{B}}^{\prime}+\omega_{13} X_{\mathrm{A}}^{\prime} X_{\mathrm{A}_{\mu} \mathrm{B}}^{\prime}\right]
\end{aligned}
$$

where a prime denotes differentiation with respect to $X_{1}$. From the known values of interaction energies and $K, S_{\mathrm{cc}}(0)$ was determined as a function of concentration for the $\mathrm{Ca}-\mathrm{Al}$ system at $1373 \mathrm{~K}$ and is shown in Fig. 5.

The enthalpy of mixing is given by

\begin{tabular}{|c|c|c|c|c|c|c|}
\hline & \multicolumn{3}{|c|}{$\begin{array}{l}\text { Interaction energies at } \\
1373 \mathrm{~K}(\mathrm{~kJ} / \mathrm{mol})\end{array}$} & \multirow{2}{*}{$K_{1373 \mathrm{~K}}$} & \multirow{2}{*}{$K_{1157 \mathrm{~K}}$} & \multirow{2}{*}{$\begin{array}{c}H^{\text {diss }} \\
\text { (kJ/mol) }\end{array}$} \\
\hline & $\omega_{12} / v_{12}$ & $\omega_{13} / v_{13}$ & $\omega_{23} / v_{23}$ & & & \\
\hline $\begin{array}{l}\text { Mole fraction } \\
\text { composition variable }{ }^{(13)}\end{array}$ & -38.587 & -16.941 & -22.078 & 0.014990 & 0.0032 & 94.85 \\
\hline $\begin{array}{l}\text { Volume fraction } \\
\text { composition variable }^{(14)}\end{array}$ & -36.800 & 0.000 & -13.000 & 0.006876 & 0.0013 & 101.23 \\
\hline
\end{tabular}

$$
H^{\mathrm{m}}=\frac{1}{\left(1+\mu X_{\mathrm{A}_{\mu} \mathrm{B}}\right)}\left(X_{\mathrm{A}} X_{\mathrm{B}} \omega_{12}+X_{\mathrm{A}} X_{\mathrm{A}_{\mu} \mathrm{B}} \omega_{13}+X_{\mathrm{B}} X_{\mathrm{A}_{\mu} \mathrm{B}} \omega_{23}\right)-\frac{X_{\mathrm{A}_{\mu} \mathrm{B}}}{\left(1+\mu X_{\mathrm{A}_{\mu} \mathrm{B}}\right)} H^{\text {diss }} .
$$

The value of the equilibrium constant at $1157 \mathrm{~K}$, the mean temperature of calorimetric measurements, and $H^{\text {diss }}$ were computed through a numerical iteration technique using the Van't Hoff equation

Table 4 Interaction energies and equilibrium constant corresponding to regular associated model for the system $\mathrm{Ca}-\mathrm{Al}$. 


$$
\frac{\partial \ln K}{\partial\left(\frac{1}{T}\right)}=-\frac{H^{\text {diss }}}{R}
$$

and experimental values for $H^{\mathrm{m}}$ reported by Sommer et al. ${ }^{(4)}$. The values of $H^{\text {diss }}$ and the equilibrium constant at $1157 \mathrm{~K}$ obtained by this procedure are listed in Table 4 . The enthalpy of mixing at $1157 \mathrm{~K}$ determined using this model is plotted in Fig. 6 along with the experimental points of Sommer et $a l .{ }^{(4)}$. The entropy of mixing at $1373 \mathrm{~K}$ was obtained from the relation,

$$
S^{\mathrm{m}}=\frac{-R}{\left(1+\mu X_{\mathrm{A}_{\mu} \mathrm{B}}\right)}\left(X_{\mathrm{A}} \ln X_{\mathrm{A}}+X_{\mathrm{B}} \ln X_{\mathrm{B}}+X_{\mathrm{A}_{\mu} \mathrm{B}} \ln X_{\mathrm{A}_{\mu} \mathrm{B}}\right)-\frac{X_{\mathrm{A}_{\mu} \mathrm{B}}}{\left(1+\mu X_{\mathrm{A}_{\mu} \mathrm{B}}\right)}\left(R \ln K+\frac{H^{\text {diss }}}{T}\right)
$$

using the known value of the equilibrium constant at $1373 \mathrm{~K}$ and $H^{\text {diss }}$. The concentration dependence of the entropy of mixing computed through the mole fraction based model is shown in Fig. 7.

\section{Model based on volume fraction variable}

If the volume of the complex is assumed to be a linearly additive function of the volume of individual atomic species then following Bhatia and Hargrove ${ }^{(14)}$ the free energy of mixing for an $\mathrm{A}_{\mu} \mathrm{B}$ type of complex is given by,

$$
G^{\mathrm{m}}=-n_{3} g+R T\left[n_{1} \ln n_{1}+n_{2} \ln n_{2}+n_{3} \ln (\mu+1) n_{3}\right]+\sum_{i<j} \sum_{i} n_{j} v_{i j} .
$$

Applying the equilibrium condition, i.e. $\left(\partial G^{\mathrm{m}} / \partial n_{3}\right)=0$, it can be shown that,

$$
n_{1}^{\mu} n_{2}=n_{3} K^{\prime} \exp (Z)
$$

where

$$
K^{\prime}=K(\mu+1) \exp (-\mu)
$$

and

$$
\begin{aligned}
Z= & (R T)^{-1}\left[\left(n_{1}-\mu n_{3}\right) v_{13}+\left(n_{2}-n_{3}\right) v_{23}\right. \\
& \left.-\left(\mu n_{2}+n_{1}\right) v_{12}\right] .
\end{aligned}
$$

Bhatia and Hargrove ${ }^{(14)}$ have suggested that eq. (19) can be solved by choosing several different sets of parameters for the interaction energies and taking $(\mu+1) G^{\mathrm{m}}$ at the stoichiometric composition as a starting approximation for the free energy of association, until a good fit to the experimental $G^{\mathrm{m}}$ is obtained. The sets of parameters so obtained for the $\mathrm{Ca}-\mathrm{Al}$ system at $1373 \mathrm{~K}$ are listed in Table 4 . The free energy of mixing as a function of concentration using this procedure is sketched in Fig. 4. The function $S_{\mathrm{cc}}(0)$ for this model is again given by eq. (14), but $S_{\mathrm{cc}}$ and $D$ are now defined by,

$$
S_{\mathrm{cc}}=\left[\sum_{i=1}^{3} \frac{\left(n_{i}^{\prime}\right)^{2}}{n_{i}}\right]^{-1}
$$

$$
D=\frac{2}{R T} \sum_{i<j} n_{i}^{\prime} n_{j}^{\prime} v_{i j}
$$

The value of $S_{\mathrm{cc}}(0)$ so obtained is plotted as a function of composition for the $\mathrm{Ca}-\mathrm{Al}$ system at $1373 \mathrm{~K}$ in Fig. 5. The enthalpy of mixing following this procedure is given by

$$
H^{\mathrm{m}}=\sum_{i<j} n_{i} n_{j} v_{i j}-n_{3} H^{\text {diss }} \text {. }
$$

The equilibrium constant $K$ at $1157 \mathrm{~K}$ and $H^{\text {diss }}$ was again obtained in a similar fashion as discussed earlier. The variation of the enthalpy of mixing with concentration derived using the model based on volume fraction for the $\mathrm{Ca}-\mathrm{Al}$ system is shown in Fig. 6. The entropy of mixing for the volume fraction based model can be represented by

$$
\begin{aligned}
S^{\mathrm{m}}= & -R\left[n_{1} \ln n_{1}+n_{2} \ln n_{2}+n_{3} \ln (\mu+1) n_{3}\right] \\
& -n_{3}\left(R \ln K+\frac{H^{\text {diss }}}{T}\right) .
\end{aligned}
$$

The entropy of mixing for the $\mathrm{Ca}-\mathrm{Al}$ system at $1373 \mathrm{~K}$ obtained from eq. (21) is plotted in Fig. 7. 


\section{Discussion}

\section{Comparison with literature}

The activities obtained in this study show significant negative deviation from Raoult's law. The data of Schurmann et al. ${ }^{(5)}$ at $1623 \mathrm{~K}$ obtained by boiling point method is also shown in Fig. 3 for comparison. Although these results are in qualitative agreement, indicating approach to ideality with increasing temperature, the temperature dependence of activity is not fully consistent with known values for enthalpy of mixing ${ }^{(4)}$ in this system. The free energy of formation at melting point of the intermetallic compound $\mathrm{Al}_{2} \mathrm{Ca}$ obtained from the results of this study combined with the enthalpies of mixing of Sommer et ll $^{\left({ }^{(4)}\right.}$ are found to be consistent $( \pm 0.70 \mathrm{~kJ} / \mathrm{g}$.at.) with the data of Notin et al. ${ }^{(1)(3)}$ for solid $\mathrm{Al}_{2} \mathrm{Ca}$.

\section{Comparison with regular associated solution models}

The derived thermodynamic quantities $G^{\mathrm{m}}$, $H^{\mathrm{m}}$ and $S_{\mathrm{cc}}(0)$ are found to be in good agreement with the experimental results. Values derived for these functions from the model based on mole fraction exhibit a slightly better fit to experimental data. Perhaps, the assumption that the volume of the complex is a linearly additive function of the volume of free atoms $^{(13)}$ is an oversimplification. However, the values for the enthalpy and free energy of dissociation of the complex derived from the model based on volume fraction composition variable, when extrapolated to lower tempera- tures, show better agreement with the data of Notin et al. ${ }^{(1)(3)}$ for the solid compound.

\section{Acknowledgements}

The authors are thankfu1 to Mrs. Thelma Pinto and Mr. A. V. Narayana for assistance in preparation of the manuscript.

\section{REFERENCES}

(1) M. Notin and J. Hertz: CALPHAD, 6 (1982), 49.

(2) E. Veleckis: J. Less-Common Metals, 80 (1981), 241.

(3) M. Notin, J. C. Gachon and J. Hertz: J. Chem. Thermodyn., 14 (1982), 425.

(4) F. Sommer, J. J. Lee and B. Predel: Z. Metallk., 74 (1983), 100.

(5) E. Schurmann, P. Funders and H. Litterscheidt: Arch. Eisenhuttenw., 46 (1975), 473.

(6) J. Valderrama and K. T. Jacob: Thermochim Acta, 21 (1977), 215.

(7) J. Valderrama and K. T. Jacob: J. Inorg. Nucl. Chem., 40 (1978), 993.

(8) K. T. Jacob: Z. Metallk., 76 (1985), 415.

(9) R. P. Iczkowski, J. L. Margrave and S. M. Robinson: J. Phys. Chem., 67 (1963), 229.

(10) R. Hultgren, R. L. Orr, P. D. Anderson and K. K. Kelly: Selected Values of Thermodynamic Properties of Elements, ASM, Metals Park, Ohio (1973).

(11) K. D. Carlson, P. W. Gilles and R. J. Thorn: J. Chem. Phys., 38 (1963), 2725.

(12) J. Eldridge and K. L. Komarek: Trans. Met. Soc. AIME, 230 (1964), 226.

(13) S. Lele and P. R. Rao: Metall. Trans., 12B (1981), 659.

(14) A. B. Bhatia and W. H. Hargrove: Phys. Rev., 10B (1974), 3186.

(15) P. J. Flory: J. Chem. Phys., 10 (1942), 51.

(16) P. J. Flory: Principles of Polymer Chemistry, Cornell Univ. Press, Ithaca, New York, (1953).

(17) A. S. Jordan: Metall. Trans., 1 (1970), 239.

(18) A. S. Jordan: Metall. Trans., 7B (1976), 191.

(19) F. Sommer: Z. Metallk., 73 (1982), 72. 